\title{
The Michael Jackson Autopsy: Insights Provided by a Forensic Anesthesiologist
}

\section{Richard J. Levy*}

Division of Anesthesiology and Pain Medicine, Children's National Medical Center, The George Washington University School of Medicine and Health Sciences, USA

\begin{abstract}
Based on toxicology findings performed on samples taken at the time of autopsy, the cause of Michael Jackson's death was determined to be acute propofol intoxication with a contributory benzodiazepine effect. The manner of death was determined by the coroner to be homicide. At the center of this case are several anesthetic medications. Insight into the toxicology, review the autopsy results, and summary of the findings are provided from a forensic anesthesiologist's point of view.
\end{abstract}

\section{Introduction}

Michael Jackson was pronounced dead on June 25, 2009 at 2:26 $\mathrm{pm}$ in the afternoon at UCLA Medical Center. He died despite two and a half hours of attempted cardiopulmonary resuscitation (CPR). At 12:22 pm, roughly thirty minutes after the 911 call from $\mathrm{Mr}$. Jackson's residence, paramedics found the pop star unresponsive and asystolic. They placed an endotracheal tube in his airway, began chest compressions, and administered epinephrine.Spontaneous circulation was never restored. Mr. Jackson remained unconscious with fixed and dilated pupils. At the direction of Mr. Jackson's physician, Dr. Conrad Murray, the decedent was taken by ambulance to UCLA Medical Center while CPR efforts continued.

When they arrived at the hospital, Mr. Jackson remained asystolic. Emergency room physicians placed three central venous catheters and an arterial balloon pump within his aorta in order to attempt to restore coronary perfusion. Death was officially pronounced at 2:26 pm and was immediately reported to the Los Angeles County Department of Coroner. The death investigation began at 5:20 pm on June 25, 2009.

Michael Jackson's autopsy was performed on June 26, 2009 at 10:00 am. Based on toxicology findings, the cause of his death was determined to be acute propofol intoxication with a contributory benzodiazepine effect. The manner of death was determined by the coroner to be homicide.Michael Jackson's personal physician, Dr. Conrad Murray, was charged with involuntary manslaughter; a felony.

On July 22, 2009, a search warrant was issued for the search and seizure of several items from Dr. Murray's self storage unit in Harris County, Texas. The sworn affidavit provided by Detective Orlando Martinez of the Los Angeles Police Department was included in the search warrant to indicate probable cause [1]. The details of the events of June 25, 2009 and the days leading up to that fateful day are detailed in this affidavit. On February 8, 2010, The Smoking Gun posted the death investigation and autopsy findings [2]. It revealed post-mortem details of Michael Jackson's medical conditions and the toxicologic evidence trail of an accidental death. At the center of this case are several anesthetic medications. The trial will focus on two potential scenarios. The prosecution will aim to show that Dr. Murray administered the propofol that killed Mr. Jackson and the defense will argue that Mr. Jackson administered propofol to himself. As a forensic anesthesiologist, I will provide insight into the toxicology, review the autopsy results from a clinician's point of view, and interpret the findings.

\section{The medical findings}

Michael Jackson was a 50 year old man. His autopsy demonstrated that he suffered from many common medical conditions. Although none of these illness and findings contributed to his death, they are of interest from a medical curiosity standpoint.

\section{Genitourinary system}

Michael Jackson's autopsy demonstrated that he had nodular prostatic hyperplasia. The prostate gland is part of the male reproductive system and the urethra courses through it. When the prostate enlarges, it can constrict the urethra and impede the flow of urine. Such constriction makes initiating the urine stream difficult, results in weak flow, dribbling after urination, the feeling that the bladder is not completely empty, urgency, and frequency [3]. About $50 \%$ of all men over the age of 75 will have some of these symptoms [3]. On autopsy, Mr. Jackson's bladder was distended and filled with urine. In life, his enlarged prostate would have resulted in urinary retention and difficulty voiding. At autopsy, a condom-type urinary catheter was found on his genitals. At the time of his death, Jackson was being treated with tamsulosin to alleviate his urinary symptoms.Tamsulosin is an alpha receptor antagonist which relaxes the prostate and alleviates the constriction on the urethra [3].

\section{Gastrointestinal system}

Examination of Michael Jackson's gastrointestinal system revealed a $2 \mathrm{~mm}$ pedunculated polyp in his sigmoid colon. Histologic evaluation of the polyp identified it as a tubular adenoma. This type of polyp accounts for about $75 \%$ of all colon polyps and can potentially become malignant if left untreated [4]. It is likely that Mr. Jackson had no symptoms from this and had no knowledge of it. A routine colonoscopy would have identified the polyp and permitted biopsy and

${ }^{*}$ Corresponding author: Levy at Division of Anesthesiology and Pain Medicine Children's National Medical Center, 111 Michigan Ave., NW, Washington, DC USA 20010, Tel: (202) 476-2025; Fax: (202) 476-4922; E-mail: rlevy@cnmc.org

Received July 10, 2011; Accepted October 24, 2011; Published October 26 2011

Citation: Levy RJ (2011) The Michael Jackson Autopsy:Insights Provided by a Forensic Anesthesiologist. J Forensic Res 2:138. doi:10.4172/2157-7145.1000138

Copyright: (c) 2011 Levy RJ. This is an open-access article distributed under the terms of the Creative Commons Attribution License, which permits unrestricted use, distribution, and reproduction in any medium, provided the original author and source are credited. 
removal. The American Cancer Society recommends routine screening colonoscopy beginning at age 50 for both men and women [4]. Follow up evaluations depend on whether or not polyps and malignancies are detected.

\section{Skeletal system}

Several x-rays were taken of Mr. Jackson's skeletal system. He had mild degenerative spondylosis of the lower thoracic spine and suffered from degenerative osteoarthritis in several joints including his lower lumbar spine and digits. He also was found to have a small cervical rib on the second to last cervical vertebrae on the right side of his neck (C7). Cervical ribs occur in $5-10 \%$ of the population and they can cause thoracic outlet syndrome [5]. It is unknown if Michael Jackson suffered symptoms from his cervical rib.Thoracic outlet syndrome results when the rib compresses or traps the brachial plexus and the subclavian artery that supply the ipsilateral hand and arm [5].Such compression often results in sharp, burning or aching pain as well as numbness, weakness, and parasthesias in the affected arm.

\section{Pulmonary system}

Microscopic examination of Michael Jackson's lungs revealed impressive and long standing abnormalities. Both lungs were markedly inflamed with bronchiolits, chronic interstitial pneumonitis, eosinophilic infiltrates, and there was evidence of fibrocollagenous scarring. In addition, there was widespread congestion in both lungs and patchy areas of hemorrhage. Furthermore, two small arteries had organizing and recanalizing thromboemboli. This means that the arteries clotted off in the past and were in the early stages of re-establishing blood flow. There was also evidence of histiocytic desquamation and focal desquamation of the respiratory lining with squamous metaplasia. This means that cells were sloughing off of the inner lining of his airways within each lung and there was a change in cell type. These findings are very abnormal. In life, such pathology could cause shortness of breath and difficulty breathing as well as a chronic cough. Michael Jackson's lung pathology would have made it difficult for him exert himself physically and probably caused him to fatigue easily.

\section{Teeth, Skin, and Hair}

Dental examination revealed a root canal along with endosseal implants and metallic and ceramic restoration of many different teeth. His skin demonstrated patches of dark pigmented and lighter less pigmented areas consistent with vitiligo. Mr. Jackson also had dark tattoos in his eyebrows and had tattooed his eyelids to look like eyeliner. He also had tattooed both of his lips pink. He was wearing a black wig kept in place by an adhesive substance. Underneath the wig, his own hair was short and tightly curled with frontal balding. Hair loss could have been the result of the incident in which Mr. Jackson's hair caught fire during the 1984 filming of a cola commercial. He had several surgical scars around the face and neck likely from prior plastic surgical procedures.

\section{A Serious Medical Diagnosis}

The combination of vitiligo, arthritis, and lung inflammation raises the concern for an autoimmune disease. In fact, in 1986, Michael Jackson was diagnosed with systemic lupus erythematosus (SLE). SLE is a serious and potentially life threatening disease that can occur at any age [6]. It affects women more commonly than men and African Americans and Asians more commonly than other races [6]. Symptoms vary widely and often flare or go into remission frequently.
Common symptoms include chest pain, fatigue, fever, hair loss, skin rash, swollen lymph nodes, sensitivity to sunlight, and mouth sores [6]. Complications from SLE include thrombosis, hemolysis, pleural and pericardial effusions, stroke, and vasculitis [6]. There is no cure for SLE and treatment usually consists of ant-inflammatory medications and steroids. Although Michael Jackson had received treatment for lupus in the past, he was not on any such therapy at the time of his death. His SLE was reportedly in remission, however, the pulmonary findings suggest that it had caused significant lung injury.

Although none of the medical findings in Michael Jackson's autopsy contributed to his death, they certainly indicate that the singer suffered from both SLE and prostatic hyperplasia.

\section{The Death Investigation}

Witness statements: On June 27, 2009, a detective from the Los Angeles Police Department interviewed Dr. Murray in the presence of his attorneys. Murray provided the following information.

Dr. Murray, a cardiologist, began treating Michael Jackson as his personal physician for insomnia six weeks prior to June 25, 2009. Each evening, he would administer propofol mixed with lidocaine to $\mathrm{Mr}$. Jackson. Murray stated that he injected Mr. Jackson with $50 \mathrm{mg}$ of propofol via an intravenous catheter (iv). The lidocaine was added in an attempt to prevent the painful stinging sensation associated with propofol injection. Dr. Murray stated that, at the time, he believed Mr. Jackson was developing an addiction to propofol. In the days prior to Mr. Jackson's death, Murray attempted to wean him off of the anesthetic. On June 22, 2009, Murray administered $25 \mathrm{mg}$ of propofol, lorazepam (a long acting benzodiazepine), and midazolam (a short acting benzodiazepine) to Michael Jackson. On June 23, 2009, Murray only gave Mr. Jackson lorazepam and midazolam and did not inject propofol. At 1:00 am on June 25, 2009, Michael Jackson called Dr. Murray, complaining of dehydration and insomnia. At 1:30 am, Murray gave Mr. Jackson a $10 \mathrm{mg}$ tablet of diazepam (a long acting benzodiazepine). This did not help Mr. Jackson fall asleep. Murray then injected $2 \mathrm{mg}$ of lorazepam thirty minutes later. Dr. Murray stated that he was monitoring Michael by using a pulse oximeter connected to Jackson's finger. This device measures oxygen saturation in the blood and is a standard of care when administering sedatives in a variety of clinical settings. At 3:00 am, Murray gave Mr. Jackson 2 mg of midazolam. Mr. Jackson remained awake. Murray then gave a subsequent $2 \mathrm{mg}$ dose of lorazepam at 5:00 am. At 7:30 am, Dr. Murray injected Michael with $2 \mathrm{mg}$ of midazolam. Mr. Jackson remained awake and repeatedly asked for and demanded a propofol injection. At 10:40 am, Murray injected $25 \mathrm{mg}$ of propofol mixed with lidocaine. According to Murray, Mr. Jackson finally fell asleep. Dr. Murray then left the bedroom to use the restroom. He stated that he was away from Mr. Jackson for no more than 2 minutes. Upon his return, Michael Jackson was unconscious and apneic. In the interview, Murray did not mention what Mr. Jackson's oxygen saturation was at the time or if the monitor had been alarming. He then pulled Mr. Jackson's body onto the bedroom floor and initiated CPR by himself. Murray stated that, at this time, he gave $0.2 \mathrm{mg}$ of flumazenil (a benzodiazepine reversal agent) to try to reverse the effect of the lorazepam and midazolam. He called Mr. Jackson's security detail by cell phone for help. They did not respond. Murray then stopped CPR, left Michael Jackson's bedside, and ran downstairs to ask Jackson's chef to send Jackson's eldest son in to help him. When Murray returned, he continued CPR. It is unclear how long he was gone for. The security detail finally arrived shortly after and called 911 . 
Murray told investigators that he was not the first doctor to administer the anesthetic, propofol to Michael Jackson. According to Murray, Mr. Jackson admitted that two doctors in Germany had previously administered Jackson the drug. In addition, in March or April of 2009, Mr. Jackson convinced Murray to arrange for an office based anesthesiologist to administer propofol to Jackson. In January of 2009, Michael Jackson met a nurse practitioner who was providing care for his three children. Mr. Jackson told her that he was fatigued. She diagnosed him with borderline-hypoglycemia. She placed Michael on a nutritional diet with a supplemental protein drink. On April 12, 2009, Mr. Jackson visited the nurse practitioner again and complained of insomnia. He asked if she was familiar with the drug propofol. She was not. Michael tried to convince her that it was safe. The practitioner subsequently read about propofol and warned Mr. Jackson not to take the medication. Michael then asked if she could obtain some propofol or if she knew of someone who could. According to the nurse practitioner, Mr. Jackson offered to pay her or anyone else whatever they wanted in exchange for it. She refused and that was the last time she saw Michael Jackson.

\section{The death scene}

Investigators went to Michael Jackson's 2-story mansion in the BelAir section of Los Angeles at 7:10 pm on June 25, 2009. They found the home to be clean and in order. They went directly to second floor bedroom where Dr. Murray was administering care to Mr. Jackson.

The room was furnished with a queen sized bed, several tables and chairs, a dresser, and a television. The bed was in disarray. On the bed, there was an impression in the sheets where Michael Jackson slept and a blue pad was present (in case of accidental voiding). Near the foot of the bed, there was a tube of toothpaste, a string of beads, and a bottle of urine. On the other side of the bed, there was a book, a pair of glasses, and a laptop computer. Several empty orange juice bottles were on a nearby table. An oxygen tank rested on the side of the bed. This tank was empty when examined on July 13, 2009. A self-inflating ventilation bag along with face mask (that was not attached to the oxygen tank) was found near where Mr. Jackson received CPR along with latex gloves, disposable needles, alcohol pads, and a box of iv catheters. There was no mention of a pulse oximeter monitor at the scene. It is unknown if the emergency responders brought the oxygen tank and ventilation bag or if these were Dr. Murray's.

An iv fluid setup was found consisting of a 1-liter bag of clear fluid, connection tubing, and a short Y-connector. A short section of iv tubing attached to the $\mathrm{Y}$-connector contained yellow tinted fluid. Two $10 \mathrm{~mL}$ syringes with some residual white fluid and multiple opened bottles of propofol were also found. Eight bottles of propofol in all were recovered. The iv setup and syringes were collected as evidence. Multiple vials of lidocaine, lorazepam, midazolam, and flumazenil were also found. Several bottles of prescription pills were in the home. These medications included clonazepam, trazodone, diazepam, lorazepam, tamsulosin, temazepam, and tizanidine. The diazepam, tamsulosin, lorazepam, and temazepam were prescribed by Dr. Murray, the clonazepam and trazodone were prescribed by a different general practitioner, and the tizanidine was prescribed by Jackson's dermatologist. Each of these medications, except for the tamsulosin, was prescribed to treat insomnia.

The witness accounts indicate that Michael Jackson craved propofol and demonstrated drug seeking behavior. His pattern of visiting various different physicians and medical caregivers in order to obtain propofol and other prescription sleep-aids is a clear example "doctor shopping". When a particular caregiver refuses or ceases to give a patient the medication they are seeking, they simply try to find another caregiver that will. It is common for such patients to reach out to several different medical providers in a variety of different specialties. These actions are classic drug addiction behavior.

\section{The Autopsy and Toxicology}

The external examination of Michael Jackson at the time of autopsy revealed gauze pads on the right side of his neck, in the antecubital region of his left and right arms, and on his left forearm. These were presumably sites where placement of iv catheters during CPR was attempted. Three large central venous catheters were in place: one in his left jugular vein and one in each femoral vein. An arterial balloon pump was in the appropriate position within the aorta through the left femoral artery and an endotracheal tube was present within the decedent's airway. These had been successfully placed by the Emergency Room team at UCLA Medical Center during the resuscitation. In the center of his chest, Mr. Jackson had a large bruise and abrasion. His sternum and several ribs were fractured. These were undoubtedly as a result of chest compressions during CPR. There were also several puncture sites in both arms, one on his left knee and one on his right ankle. It is unclear if any of these represented sites where intravenous medications were administered by Dr. Murray. The anesthesiology consultant for the case stated that an iv catheter was noted in Mr. Jackson's left leg, however, the autopsy report did not mention such a catheter.

Of note, the blood within Michael Jackson's heart was unclotted at the time of autopsy. The autopsy was performed on June 26, 2009 at 10:00 am; roughly 20 hours after the time of death. Finding unclotted blood at the time of autopsy is consistent with hypoxia. This is often seen in cases of asphyxia and sudden infant death syndrome, for example [7]. It suggests that Mr. Jackson was apneic prior to his death, resulting in a critical decline in oxygen saturation and subsequent asystole.

Toxicology was performed by the coroner's office on Michael Jackson's blood (samples drawn at UCLA Medical Center and at the time of autopsy), vitreous, liver, stomach contents, and urine (the bottle collected at the scene and taken from his bladder during the autopsy). In addition, tests were performed on the $10 \mathrm{~mL}$ syringes and iv fluid setup and tubing. These results were critical to determining the cause of Michael Jackson's death (table). Propofol was detected in his blood, vitreous, liver, stomach contents, and in both urine samples. The levels of propofol found in each sample of blood were within the therapeutic range. This means that there was enough propofol in his system at the time of death to render him unconscious.Lidocaine was also detected in each specimen except for the vitreous. Three different benzodiazepines along with a metabolite of diazepam (nordiazepine) were detected in Mr. Jackson's blood. Midazolam was also present in his urine. These findings indicate that Michael had either taken or was given diazepam, lorazepam, and midazolam within hours prior to his death. Ephedrine was detected in the two urine samples.

The two $10 \mathrm{~mL}$ syringes found at the scene each contained a small amount of white fluid (0.19 grams and 0.17 grams). Propofol and lidocaine were detected in one syringe and propofol, lidocaine, and flumazenil were detected in the other. The short section of iv tubing attached to the $\mathrm{Y}$-connector that contained yellow tinted fluid was tested and was also found to contain propofol, lidocaine, and flumazenil. No drugs were detected in the rest of the intravenous tubing or 1-liter bag with clear fluid. These fluids were presumably saline or some other routine medical delivery solution. 
In order for an accurate interpretation, it is important to review some important pharmacologic properties of propofol.

\section{Propfol}

Propofol is a potent anesthetic drug that rapidly causes sedation and unconsciousness when intravenously injected [8,9]. Since 1986, it has been used world-wide in clinical settings and has become the anesthesiologist's drug of choice to induce general anesthesia and to provide sedation for a variety of procedures $[9,10]$. Propofol is administered as a single injection to induce unconsciousness or as a continuous infusion to maintain a desired level of sedation [11]. It is a very short acting drug and patients rapidly awaken following injection if an infusion is not initiated [11].

In 2009, propofol was not a controlled substance scheduled by the U.S. Drug Enforcement Agency. However, today, the drug is in the process of being reclassified. Hospitals usually have policies to restrict propofol use to specific areas within the hospital and limit those capable of administering it to qualified personnel such as anesthesiologists and critical care physicians. In addition to being clinically indicated for anesthesia and sedation, propofol has also been used to treat seizures, migraine and tension headaches, severe alcohol withdrawal and delirium tremens, and has been used to facilitate narcotic detoxification $[8,11]$. It has never been indicated to treat insomnia.

Propofol is insoluble in water and the current formulation is an emulsion of soybean oil, glycerol, and egg lecithin. This lipid formula gives the drug its characteristic and unique white color [8]. In his interview with investigators, Dr. Murray told investigators that Michael Jackson craved propofol and called it "his milk" (because of the white color). Certain preparations of propofol will turn yellow when exposed to air for 6 to 7 hours. Propofol causes a burning pain when it is injected, so many anesthesiologists will attempt to anesthetize the vein with lidocaine, a local anesthetic. This can be done either by injecting lidocaine into the vein prior to propofol administration or by mixing lidocaine with propofol in the syringe. According to Murray, Mr. Jackson was well-versed in the use of lidocaine to limit or prevent propofol's pain on injection.

Propofol induces unconsciousness rapidly. Loss of consciousness occurs 100 seconds following a $2.5 \mathrm{mg}$ per kilogram injection and lasts for 5-10 minutes [8]. It blunts the respiratory drive and relaxes oropharyngeal muscle tone, potentially resulting in airway obstruction. Without proper management by an experienced provider, a single injection of propofol can result in apnea, hypoxia, and death [8]. Furthermore, injection of $2.5 \mathrm{mg}$ per kilogram results in a $25-40 \%$ reduction in blood pressure [8]. This decrease in blood pressure is more pronounced in dehydrated patients. These effects make propofol potentially dangerous and lethal when injected by inexperienced personnel or self administered. Following injection, propofol is rapidly eliminated by the body. It is metabolized in the liver and excreted into the urine by the kidneys [8]. Thus, propofol does not accumulate in the body.

The abuse potential of propofol was not recognized until 1992. Since then, 38 cases of propofol abuse have been published [10]. Propofol has increasingly become a drug of abuse largely because it is easily accessible, it has a rapid onset of action, and the duration of action is ultra-short without long term side effects [10].Medical professionals and healthcare workers represent the largest group of known propofol abusers [10]. Of these personnel, anesthesiologists and nurse anesthetists are the most common offenders. The most likely rationale for this is familiarity with the drug and previously unregulated access to it. Recent studies suggest that propofol diversion and abuse are on the rise [12].

The majority of cases of propofol abuse involve use of the drug for recreational purposes, stress relief, and to alleviate insomnia. In one report, propofol dependency was described in a lay person following a propofol prescription for the treatment of tension headaches [11]. The average age of known propofol abusers is about 30 years of age and most abusers are male [13]. In most cases, propofol was used in addition to other drugs of abuse and the user had a history of drug dependency [13].

Physical dependence has not been described in propofol abusers, however, psychological dependence is quite common $[10,13]$. This is because propofol can cause euphoria, stress and tension relief, sexual fantasies and dreams, and sexual disinhibition [10,13]. These effects of propofol lead to drug craving and loss of control over the amount and frequency of drug injected as well as continued use of propofol despite adverse consequences. Chronic propofol abuse can result in tolerance and repeated injections exceeding 100 times per day have been reported [14].

Propofol abuse and recreational use often result in death because of the rapid onset of unconsciousness and apnea following injection [10]. Thirty-seven percent of the 38 published cases of abuse were fatal [10]. The majority of these propofol related deaths resulted from accidental overdose or suicide. Recently, the first case of first degree murder with propofol was reported [10].

Blood levels of propofol in most propofol related deaths are usually within the therapeutic range $(1.3-6.8 \mu \mathrm{g} / \mathrm{mL})$. This means that propofol induced unconsciousness and the cause of death was likely due to apnea with subsequent hypoxia. As with other drugs of abuse, a specific "lethal level" may not be necessary to conclude that death was caused by propofol injection. Simply detecting it in blood indicates it was injected prior to death and at least contributed to if not caused the death.

Several accidental propofol related deaths have been reported. A 26 year old male ICU nurse who was a known propofol abuser was found dead in his apartment surrounded by several empty and partially empty propofol vials along with two syringes [15]. His autopsy demonstrated several recent and partially scarred needle marks on his arms, wrists, and hands. Propofol was detected in his hair, blood, urine, brain, and liver.

A 27 year old male nurse anesthetist was found dead at his home with three empty propofol vials next to him [16]. Unopened propofol bottles were found in his car. Several needle marks in his skin suggested chronic abuse. His autopsy revealed pulmonary hemorrhage and inflammation of the pancreas. Propofol was detected in his blood, bile, and urine.

A 44 year old female nurse anesthetist was found dead at her home with an empty vial of midazolam and a syringe near her body [17]. Toxicology revealed propofol, midazolam, and alcohol in her blood. Analysis of her hair demonstrated propofol and midazolam in several segments indicating repetitive abuse for 6 months prior to her death.

A 21 year old male lay person purchased propofol online using an internet bidding system [18]. He was found with an iv catheter in situ that he had placed in order to inject propofol several times a day. Propofol was detected in his blood. 
A 38 year old known propofol abusing female anesthesiologist was found dead in a hospital on call room [19]. She was kneeling on the floor facing downward with three empty vials of propofol and two used syringes next to her. Autopsy demonstrated numerous needle marks with recent and older hemorrhages in both arms, two iv catheters secured in each wrist, and pulmonary edema. Propofol was detected in her blood.

Seven other accidental propofol related deaths have been reported in members of anesthesiology residency programs [10]. Six of the victims were anesthesiology residents and one was an anesthesia technician. All were propofol abusers.

Two suicides have also been reported in which propofol was used to operationalize the plan. In the first case, a 29 year old female radiologist committed suicide by self-administering propofol [20]. Propofol was detected in her blood and liver.

In another case, a 37 year old male medical doctor committed suicide with propofol after he recently broke off an extra-marital affair [21]. He was found dead, lying on his back on the bed of a rented room. Two needles had been inserted into the dorsum of his left and right hands. Each was attached to an iv fluid delivery system. Eight empty propofol vials were found at the scene. His body was moderately decomposed and autopsy findings were fairly unremarkable. Propofol was detected in his blood, liver, kidney, and brain. It was calculated that he self-administered about $1600 \mathrm{mg}$ of propofol. Of note, Dr. Murray claimed that he only gave Michael Jackson $25 \mathrm{mg}$ of propofol the day he died.

To date, there has only been one case of murder by propofol injection [10]. The details are as follows. A 24 year old University of Florida student was found dead in her house in 2005 near Gainesville. Syringes, needles, and 2 empty propofol vials were found in grocery store bags outside of her house next to her garbage cans. Autopsy demonstrated a pinpoint puncture wound in the crease of her left elbow with hemorrhage directly over a superficial vein. Toxicology assessment detected propofol in her blood. The medical examiner concluded that the woman's death was homicide caused by a lethal dose of propofol administered by a person skilled in iv injection.

Investigation of the propofol bottle lot numbers found at the crime scene indicated that the vials were obtained from a University of Florida hospital. Upon further investigation it was determined that the propofol bottles had been removed from the hospital by a male ICU nurse. He had acquired the propofol approximately 5 to 6 days prior to the murder.

Thorough questioning of the nurse's former roommate revealed important details and a potential motive. The roommate had previously introduced the nurse to the victim. The male nurse soon became infatuated and obsessed with the victim. After learning that the victim had gotten engaged to her boyfriend of 4 years, the nurse became enraged and planned to kill her. Detectives learned that the victim suffered from chronic migraine headaches. She apparently trusted the nurse and he convinced her that he would relieve her symptoms with propofol. One week after her engagement, the male nurse injected the victim with the lethal dose of propofol.

The nurse left the country and a few weeks later he was apprehended in the West African Republic of Senegal. He was escorted to the Alachua County Department of the Jail by the US Marshall's Service and was ultimately tried and convicted of first degree murder. He was sentenced to life in prison without parole.

Jackson's death has also been determined to be a homicide. This is because the coroner concluded that:

1. Propofol and benzodiazepines were administered by another person.

2. Propofol was injected in a non-hospital setting without appropriate medical indication.

3. The standard of care for administering propofol was not met.

4. There was no evidence that Michael Jackson administered propofol to himself.

The prosecution's case will hinge on the evidence that Dr. Murray administered the medications to Mr. Jackson. The defense will try to demonstrate that Mr. Jackson may have possibly administered propofol to himself prior to his death. Is this a homicide, suicide, or accidental death?

\section{Whodunnit?}

The prosecution's scenario: Dr. Murray administered benzodiazepines and propofol mixed with lidocaine to Michael Jackson in the pop star's bedroom. After Mr. Jackson lost consciousness, Murray left his patient to go to the bathroom. During the time that Murray was out of the room, Michael either became apneic or his airway became obstructed. He soon became hypoxic and asystolic. When Murray returned to the bedside, he recognized that Mr. Jackson was not breathing. He drew up flumazenil in the same syringe that previously had propofol and lidocaine in it and injected the medication to try to reverse the benzodiazepine effect. Nothing happened. Murray then began CPR.

Evidence that supports this theory is Murray's own testimony. He admitted that he gave Mr. Jackson benzodiazepines and propofol with lidocaine. The objective evidence that supports the prosecution's theory is that the amounts of propofol, lidocaine, and benzodiazepines in Michael Jackson's blood confirm that these medications were given in the hours prior to death. Furthermore, the amount of propofol in the blood was within the therapeutic range. Thus, it is likely that propofol caused apnea or an obstructed airway.

There is a problem with this version of the story, though. Dr. Murray stated that he only administered $25 \mathrm{mg}$ of propofol to Mr. Jackson. At the time of death, Michael weighed approximately 60 kilograms. The $25 \mathrm{mg}$ dose, less than 0.5 milligrams per kilogram, is incredibly small. Although some patients may have a mild sedative effect from this propofol dose, they would not become unconscious unless there were extremely hypovolemic or had significant cardiac dysfunction. Jackson had neither of these conditions. Also, this small dose of propofol would not result in the blood levels that were detected in the toxologic analysis. Furthermore, since Michael was receiving propofol almost every night, he would have likely developed some tolerance to the drug. So, something doesn't add up. The prosecution would say that Dr. Murray is not being truthful about the dose of propofol he used. $\mathrm{He}$ must have administered more. The total injected dose was probably in the $120 \mathrm{mg}$ to $180 \mathrm{mg}$ range (2-3 $\mathrm{mg}$ per kilogram).

The lidocaine concentrations found in the blood are consistent with a $2 \mathrm{mg}$ per kilogram injection about one hour prior to Michael's death [22]. Most anesthesiologists combine $40 \mathrm{mg}$ of lidocaine with 


\begin{tabular}{|l|l|l|l|l|l|l|l|l|}
\hline Drug & Heart blood & Hospital blood & Femoral blood & Vitreous & Liver & Stomach contents (in 70 $\mathbf{m L}$ ) & Urine & Urine at the scene \\
\hline Propofol & 3.2 & 4.1 & 2.6 & $<0.40$ & 6.2 & $0.13 \mathrm{mg}$ & 0.15 \\
\hline Lidocaine & 0.68 & 0.51 & 0.84 & - & 0.45 & $1.6 \mathrm{mg}$ & $<0.10$ \\
\hline Diazepam & $<0.10$ & present & - & - & - & - & present & present \\
\hline Nordiazepam & $<0.05$ & - & - & - & - & - & - \\
\hline Lorazepam & 0.162 & - & 0.169 & - & - & - & - \\
\hline Midazolam & 0.0046 & - & - & - & - & - & - \\
\hline Ephedrine & ND & - & - & - & - & - & - \\
\hline
\end{tabular}

Levels are presented in $\mu \mathrm{g}$ per $\mathrm{mL}$ or $\mu \mathrm{g}$ per gram. $\mathrm{mL}$; milliliters, mg; milligrams, ND; not detected.

Table 1: Summary of Toxicology Findings.

$180 \mathrm{mg}$ of propofol in a syringe when they mix the two for injection. The toxicology suggests that Michael received between 60 and $120 \mathrm{mg}$ of intravenous lidocaine. Depending on how Murray mixed the two drugs, if he had only given $25 \mathrm{mg}$ of propofol, then he would have only given about $5.5 \mathrm{mg}$ of lidocaine. This would have been barely detectable in the blood. On the other hand, an intravenous injection of $60 \mathrm{mg}$ of lidocaine equates to a dose of roughly $270 \mathrm{mg}$ of propofol (more than $5 \mathrm{mg}$ per kilogram) when using a standard lidocaine/propofol mixture. Such a dose of propofol would have been more than adequate induce unconsciousness and apnea.

The defense's scenario: Dr. Murray administered benzodiazepines and propofol mixed with lidocaine to Michael Jackson in the pop star's bedroom. After Mr. Jackson fell asleep, Murray went to the bathroom. During the time that Murray was out of the room, Michael Jackson, in a semi-awake state, administered the lethal dose of propofol to himself. He either injected propofol into his iv catheter himself, attempted to drink propofol, or both. The defense is essentially arguing that $\mathrm{Mr}$. Jackson's death was an accidental death caused by his own actions.

What is the evidence to support this theory? First, the blood levels of propofol would certainly reflect a potentially lethal dose of propofol regardless of who injected it. Could Michael Jackson have injected propofol into his own vein? It may be possible. He had seen the procedure enough times in the past so that he would have understood the logistics. The anesthesiology consultant to the coroner stated that, because the injection port in the iv tubing setup was $13.5 \mathrm{~cm}$ from the tip of the iv catheter in his left leg, self-injection would be awkward and unlikely. The consultant never stated that it was impossible.

How about ingestion of propofol as a contributor? The evidence to support this is that his stomach contents contained both propofol and lidocaine. The only way these drugs could have entered his stomach prior to death is if they were ingested. Only $0.13 \mathrm{mg}$ of propofol was detected in the $70 \mathrm{~mL}$ of stomach contents. This is an extremely small amount of propofol. However, the fact that both drugs were detected indicates that they came from the same syringe in which both medications were mixed. Proving that Michael Jackson injected himself with propofol or drank from the syringe is very difficult. One possible technique would have been to perform fingerprint analysis on the propofol bottles and syringes. Certainly, finding the decedent's fingerprints on the syringes would not rule out the possibility that he handled these earlier in the day or that someone placed them in his hands after he died. However, to my knowledge, fingerprint analysis was never done.

The defense will argue that oral ingestion of propofol can result in sedation and unconsciousness. What is the evidence? There are only two related publications on the matter. In the first study, propofol absorption via rectal suppository ( $55 \mathrm{mg}$ per kilogram) in 6 week old piglets was evaluated [23]. None of the piglets became sedated with rectal propofol and blood levels of propofol were 100-fold lower than those achieved following intravenous injection. The second relevant study assessed propofol absorption following oral administration in rats [24]. In this work, propofol was shown to undergo extensive metabolism in the intestine and only $10 \%$ of the ingested dose reached the circulation. As with rectal absorption, the resultant blood levels of propofol following oral administration were 100 times less than parenteral injection. Thus, in order to become unconscious from propofol ingestion, Michael Jackson would have had to drink about $12,000 \mathrm{mg}$ of propofol (over 1-liter in volume). This is a very unlikely scenario.

It is possible, however, that Mr. Jackson attempted to drink the drug. Furthermore, one cannot rule out the possibility that he may have intravenously administered propofol himself. Another scenario is that someone else may have deliberately injected the contents of a syringe of propofol into the decedent's esophagus in the peri-mortem period to make it appear as if Mr. Jackson ingested the drug. This would imply that the person: 1 . knew that the coroner would check stomach contents for medications, 2. knew that finding propofol in the stomach would provide an alibi, and 3. attempted to divert blame to the decedent.

Neither of these scenarios addresses the ephedrine in Mr. Jackson's urine or why flumazenil was detected in the same syringe as propofol and lidocaine. Ephedrine is a stimulant. In the US, ephedrine is controlled by the FDA and they have put strict limits on maximum daily dosage. It is unknown how ephedrine was taken by or administered to $\mathrm{Mr}$. Jackson. It is quite possible that he was using this stimulant to help him work through exhaustion and lethargy as he prepared for his upcoming concert tour. Of note, patients who take or receive ephedrine while taking serotonin-reuptake inhibitors, such as trazodone, could have a fatal reaction (Michael Jackson was taking trazodone). Since there was no ephedrine detected in the decedent's blood, it played no role in his death and was not given to him that evening. So it is unclear how ephedrine fits in to the story.

Flumazenil is a pharmacologic agent used to reverse the effects of benzodiazepines. It is strictly avoided in patients who have been chronically taking benzodiazepines because it can result in seizures, withdrawal, or life threatening arrhythmias. Thus, it is would have been contraindicated for Mr. Jackson. Furthermore, if a clinician wanted to reverse the sedative effect of benzodiazepines, they certainly would not inject flumazenil along with propofol. This is because additional propofol administration would only deepen the level of sedation and would antagonize the situation. Finding flumazenil mixed with propofol likely indicates that Dr. Murray hurriedly prepared the reversal agent in a syringe that he had previously used for propofol injection. 
Citation: Levy RJ (2011) The Michael Jackson Autopsy:Insights Provided by a Forensic Anesthesiologist. J Forensic Res 2:138. doi:10.4172/21577145.1000138

\section{Summary}

There is no question that Dr. Murray was irresponsible, medically negligent, and did not follow the standard of care. However, were his actions criminal? Did he inject the lethal dose or did Michael Jackson? It will be up to the legal system and the jury to determine if Dr. Murray is guilty of involuntary manslaughter. Regardless of the outcome of the trial, the Michael Jackson death case will forevermore provide a high profile example of drug addiction, manipulation, and the dangers of the anesthetic, propofol.

\section{References}

1. http://i.cdn.turner.com/cnn/2009/images/08/24/murray.search.warrant affadavits.pdf. Accessed September 14, 2011.

2. http://www.thesmokinggun.com/documents/crime/michael-jackson-autopsyreport.AccessedSeptember 14, 2011.

3. Lepor $\mathrm{H}$ (2011) Medical treatment of benign prostatic hyperplasia. Rev Urol 13:20-33.

4. Winawer SJ, Zauber AG, Fletcher RH,Stillman JS, O'brien MJ, et al. (2006) Guidelines for colonoscopy surveillance after polypectomy: a consensus update by the US Multi-Society Task Force on Colorectal Cancer and the American Cancer Society. CA Cancer J Clin 56:143-159.

5. Loscertales J, Congregado M, Jiménez Merchán R (2011) First rib resection using videothorascopy for the treatment of thoracic outlet syndrome. Arch Bronconeumol 47: 204-207

6. Ben-Menachem E (2010) Review article: systemic lupus erythematosus: a review for anesthesiologists. Anesth Analg 111:665-676.

7. Goldwater PN (2003) Sudden infant death syndrome: a critical review of approaches to research. Arch Dis Child 88:1095-1100.

8. Marik PE (2004) Propofol: therapeutic indications and side-effects. Curr Pharm Des 10:3639-3649.

9. Abad-Santos F, Gálvez-Múgica MA, Santos MA, Novalbos J, Gallego-Sandín $S$, et al. (2003) Pharmacokinetics and pharmacodynamics of a single bolus of propofol 2\% in healthy volunteers. J Clin Pharmacol 43:397-405.

10. Kirby RR, Colaw JM, Douglas MM (2009) Death from propofol: accident, suicide, or murder? Anesth Analg 108:1182-1184.
11. Schneider U, Rada D, Rollnik JD, Passie T, Emrich HM (2001) Propofol dependency after treatment of tension headache. Addict Biol 6: 263-265.

12. Wischmeyer PE, Johnson BR, Wilson JE, Dingmann C, Bachman HM, et al (2007) A survey of propofol abuse in academic anesthesia programs. Anesth Analg 105:1066-1071.

13. Roussin A, Montastruc JL, Lapeyre-Mestre M (2007) Pharmacological and clinical evidences on the potential for abuse and dependence of propofol: a review of the literature. Fundam Clin Pharmacol 21:459-466.

14. Soyka M, Schutz CG (1997) Propofol dependency. Addiction 92:1369-1370.

15. Iwersen-Bergmann $S$, Rösner $P$, Kühnau HC, Junge M, Schmoldt $A$ (2001) Death after excessive propofol abuse. Int J Legal Med 114:248-251.

16. Roussin A, Mirepoix M, Lassabe G, Dumestre-Toulet V, Gardette V, et al. (2006) Death related to a recreational abuse of propofol at therapeutic dose range. Br J Anaesth. 97:268.

17. Cirimele V, Kintz P, Doray S, Ludes B (2002) Determination of chronic abuse of the anaesthetic agents midazolam and propofol as demonstrated by hair analysis. Int J Legal Med 116:54-57.

18. Strehier M, Preuss J, Wollersen H, Madea B (2006) Lethal mixed intoxication with propofol in a medical layman. Arch Kriminol 217:153-160.

19. Kranioti EF, Mavroforou A, Mylonakis P, Michalodimitrakis M (2007) Lethal self administration of propofol (Diprivan). A case report and review of the literature. Forensic Sci Int 167:56-58.

20. Drummer $\mathrm{OH}$ (1992) A fatality due to propofol poisoning. J Forensic Sci 37:1186-1189.

21. Chao TC, Lo DS, Chui PP, Koh TH (1994) The first fatal 2,6-di-isopropylphenol (propofol) poisoning in Singapore: a case report. Forensic Sci Int 66:1-7.

22. Tsai PS, Buerkle H, Huang LT, Lee TC, Yang LC, et al. (1998) Lidocaine concentrations in plasma and cerebrospinal fluid after systemic bolus administration in humans. Anesth Analg 87:601-604.

23. Cozanitis DA, Levonen K, Marvola M, Rosenberg PH, Sandholm M (1991) A comparative study of intravenous and rectal administration of propofol in piglets. Acta Anaesthesiol Scand 35:575-577.

24. Raoof AA, Augustijns PF, Verbeeck RK (1996) In vivo assessment of intestinal, hepatic, and pulmonary first pass metabolism of propofol in the rat. Pharm Res 13:891-895. 